\title{
Price Comparison, Price Competition, And The Effects Of ShopBots
}

Kirsten A. Passyn, Salisbury University, USA

Memo Diriker, Salisbury University, USA

Robert B. Settle, Salisbury University, USA

\begin{abstract}
Two ShopBots were used to determine high-to-low price dispersion for identical models of 25 consumer durables, in 2007 and again in 2011, revealing substantial but declining price dispersion ratios. A survey of 1,135 American online shoppers revealed their dependence on ShopBots and frequency of other online shopping actions. Typical respondent reported they "very often" used search sites to locate what they wanted. Nearly 30 percent used the most often named price comparison site, Yahoo! Shopping, in the past year, suggesting substantial potential for future price rationalization. Several customer relationship management tools online merchants might use to avoid the resulting direct price competition are discussed. Finally, the impact of mcommerce, tablets, and apps on online price comparison behavior is explored.
\end{abstract}

Keywords: Consumer Behavior; Database Marketing; Direct Marketing; Electronic Commerce; Online Shopping; Price Dispersion

\section{INTRODUCTION}

s annual online shopping in North America reaches the \$200 Billion mark (Lumry, 2011), the emergence of ShopBots such as Yahoo! Shopping and Google Product Search has facilitated consumers' ability to gather price and product information, virtually mitigating search costs. It was therefore initially assumed that as ShopBots became increasingly prevalent on-line merchants would come under increased price competition, eventually leading to price convergence. With ShopBots now the third most popular online shopping option after eBay and Amazon, we reassess the impact of ShopBots on price as they reach their tipping point. Finally, we further expand the discussion to explore the impact of m-commerce, tablets, and apps on online price comparison behavior.

\section{INFORMATION SEARCH}

While virtually all consumer purchase decisions are based on the possession or acquisition of information, this is especially true for purchases of substantial value and importance to the buyer. Such durable consumer goods, as well as services of substantial importance are the kinds of purchases that evoke more intensive search. (Schiffman \& Kanuk, 2007) There is however an opportunity cost associated with the time spent searching. As search costs increase, consumers search less, evaluating fewer options and allowing for great price discrepancy. (Stahl 1989) Conversely, decreasing search costs reduces price dispersion, increases price competition, and will ultimately commoditize markets. (Smith 2004)

\section{ShopBots}

Shopbots are online product search and comparison facilities especially well suited to providing product and price information, quickly and easily. By presenting comparison information on salient criteria (e.g. price) from multiple vendors of a specific product, online shopping aids can increase the number of alternatives considered, while significantly reducing search time and costs. (Vijayasarathy \& Joseph) In fact ShopBots provide 'one-click' access to price and product information from numerous competing retailers reducing buyer search cost for product 
and price information by at least 30-fold compared to telephone-based shopping and even more compared to physically visiting the retailers. (Brynjolfsson, Dick, \& Smith, 2004)

\section{Branding and Uniformity among Products}

Unique designs and custom-made goods may be available from only one vendor, but that is rarely the case for the great bulk of consumer durable purchases. Whether tires for the car or a new set of golf clubs, a lawn mower or a plasma television set, manufactured goods are branded and identified by specific model, virtually without exception. Uniformity among individual products of a particular make and model is nearly perfect.

This implies that once a buyer has decided what to purchase, in terms of brand and model, there are only a few distinctions among online vendors of the goods. In many, and probably most, cases the main distinguishing factor is price. If this is the case, price comparison will determine, in large measure, where the shopper will buy. Under these conditions, vendors of such products are cast into direct price competition. These products and situations are the focus of this research.

\section{Branding and Distinction among Vendors}

While the item submitted for price comparison may be identical, the vendors are not likely to be so. If they were, a consumer aware of price dispersion would almost certainly choose the lowest price offering. Prices would be "rationalized," and price dispersion would be minimized or eliminated. (Stahl, 1989) While the importance of the vendor has been realized in the in-store environment, the factors that distinguish among on-line vendors are much less distinctive. Still previous research has shown that consumers who search intensely are less price sensitive, reflecting their increasing weight on retail differentiation in delivery and reliability. (Brynjolfsson et al., 2004) To the degree that shoppers select vendors whose prices are not the lowest, the choices might result from two basic factors: (1) The buyers are ignorant of the price dispersion, or (2) they perceive significant differences among the vendors of the goods that make some preferable to others despite higher prices. This research will explore both of those factors.

\section{Background}

Product search and price comparison site usage is growing rapidly. With this growth, there is an evolving literature reporting on the effects of online price comparison. (Haubl \& Trifts, 2000; Kocas, 2002, 2005; Ratchford, Pan, \& Shankar, 2003) While some have substantial theoretical and conceptual relevance, few provide significant practical insights for online marketers.

Some previous studies are based on purchase of relatively inexpensive goods, such as books, detergents or paper towels. (Chevalier \& Goolsbee, 2003; Clay, Krishnan, \& Wolff, 2001; Degeratu, Rangaswamy, \& Wu, 2000) Certainly there are price considerations for such items, but for the most part they are not likely to warrant extensive online product search and price comparisons. It would appear that shoppers would regard such small price disparities as negligible, if not trivial. Research based on "small-ticket" purchases have inherent limits to the degree results can be generalized to more expensive goods. As a consequence, this study focuses on consumer durable goods of substantial value.

\section{The Role of Ignorance}

Economists have long assumed that price dispersion for "commodities" arises from ignorance of price differentials. (Burdett \& Judd, 1983; Varian, 1980) Thus, if buyers become aware of price dispersion (e.g., in a "perfect" market), they would buy only from vendors with the lowest prices while supplies lasted, prices would be "rationalized," and dispersion would be eliminated. In such circumstances, price dispersion is attributable only to ignorance of the existence of lower prices. But commodity markets are a special case, where both the commodity and the vendors are identical. This is ordinarily not so for durable consumer goods. 


\section{Distinctions among Vendors}

While the consumer durable product for which the online shopper is searching may be identical from one seller to another, the vendors are virtually never so. Consumers' choice of online search strategy are affected significantly by buyers' attitude toward the price offered by their preferred online seller, their perception of online price dispersion, and their awareness of shopping agents. (Sen, King, \& Shaw, 2006) Usually there are differences, or at least perceived differences in vendor reputation, reliability, transaction and payment factors, delivery options, and the like.

Of particular importance in the on-line environment are perceptions of vendor reputation and reliability. In fact previous research has indicated that the number one factor for success in on-line contexts is trust (Gao and $\mathrm{Wu}$, 2010). However, the number one concern for online shoppers across all segments continues to be privacy and security, (Passyn, Diriker, and Settle 2011) suggesting perhaps that consumers are hesitant to try unknown/unused vendors. So, even if there are price disparities among sellers, the buyer may choose a higher-priced offering because of preference for a specific vendor - because of trust and loyalty.

It can be concluded, then, that if there are substantial price disparities among online sellers of identical consumer durables, the differences might be attributable to either or both (a) shoppers' ignorance of lower prices, and/or (b) preference for particular vendors over others with lower prices. Thus, if and when ignorance of price dispersion is reduced or eliminated by extensive use of online product search and price comparison facilities, the only factors shielding online marketers from direct price competition are those that distinguish one seller from another. Research indicates that the stores with loyal customers, or with a preference for their brands, can attain higher profits further into the diffusion process. (Kocas, 2002)

This study is critical at this point in time given the increasing frequency with which consumers are using ShopBots. In 2010 Nextag brought in an average of $17 \mathrm{M}$ visitors a month, Pricegrabber $24 \mathrm{M}$ visitors a month and Bizrate up to $40 \mathrm{M}$ visitors a month. (Fasce 2011) Although it is both difficult to assess unique visitors across sights and the actual number of internet shoppers, (estimated at $98 \mathrm{M}$ in 2010), given the explosion in ShopBot users the tipping point for ShopBots is eminent. Therefore has price dispersion been virtually eliminated among on-line goods? If very large price differences for identical goods prevail among online vendors, is it a result of ignorance among a portion of consumers or differences among vendors?

\section{Research Focus}

The objectives of this research are: (1) To gauge the degree of current internet buyers' dependence on price comparison search engines, (2) to estimate the existing price dispersion among identical goods for a variety of consumer durables, (3) to compare price dispersion among identical goods from today versus 4 years ago (4) to assess the future potential for substantial price rationalization, and (5) to suggest effective marketing strategies for consumer goods marketers faced with increased, direct price competition.

\section{METHODOLOGY}

A survey of 1,135 adult consumers residing in the Mid-Atlantic region was conducted. The questionnaires were delivered and retrieved by university student field workers who were assigned a quota, based on the age and sex of the respondents. To qualify for participation, respondents were required to have access to a computer at home and a high speed internet connection. They must also have made at least two online purchases in the past year. Although no minimum value was specified in the quota, the number and value of purchases were measured in the questionnaire.

\section{Survey Questionnaire}

The self-administered survey questionnaire included a list of 16 online shopping actions to which respondents indicated how often they performed each using a 5-point verbal frequency scale. Ten of the most popular price comparison websites were listed in alphabetical order and respondents indicated how often, if at all, they had visited each site during the past year. 
Respondent were questioned about their frequency of computer use, internet and web activity, and online shopping and buying behavior. Lastly, they revealed their demographic status. They indicated their sex, age, marital status, education level, employment category, occupational category, home ownership and family income in the demographic section of the questionnaire. These data measured field worker adherence to quota specifications, as well as indicating the nature of the population represented.

\section{Audit of Price Dispersion}

If there were, at present, only slight disparities among online sellers of identical consumer durables, it might be concluded that little, if any additional price rationalization could be expected. Casual perusal of internet pricing for consumer durables indicates quite the contrary. Therefore despite the explosion of ShopBot usage price dispersion persists. However, a comparison analysis between 2007 and 2011 indicates that price dispersion is slightly reduced.

An array of 25 different consumer durable items was selected on a judgment basis to represent a variety of products used in various consumer activities and pursuits. For each product line or class, a specific model was selected and specified by number and description; to the extent that identical models were available the same model numbers were used in 2011 as 2007 . However, when model numbers were no longer available new model numbers were selected based on similarity in product description. Thus price comparisons within years are of precisely identical goods, and across years either identical or the most similar models available are compared. As we are not concerned with absolute price difference across time periods but the change in price dispersion, changes in model numbers between 2007 and 2011 is not problematic. These items were than submitted to price comparisons using both Yahoo! Shopping and Google Product Search sites. Only prices for new goods available directly from the online marketers' websites are shown, together with the ratio of high to low price in for each product example. Prices listed by auction sites (e.g., eBay) were ignored. Similarly, prices listed by sited specifying "new and used," (e.g., Amazon) as well as prices for "open box" or refurbished goods were excluded. The highest and lowest prices for exactly the same items were recorded from each site during July 2007 and then again in July 2011.

\section{RESULTS}

\section{Existing Price Disparities}

The various consumer durables high and low prices for 2007 and 2011 are listed in Table 1 for Yahoo! Shopping and Table 2 for Google Product Search. Items are listed from maximum increasing price dispersion ratio difference to maximum decreasing price dispersion ratio difference. The correlations between the high prices and low prices from Yahoo! Shopping and Google Product Search sites were 0.998 and 0.999, respectively, and there was a correlation of 0.995 between the high-to-low differences between the two sites. Even though the prices from the two sites were highly correlated, a correlation coefficient of only 0.526 indicates there is substantial variation between the two price disparity ratio vectors.

Inspection of the type of goods offers little explanation for the differences in price disparity from one kind of product to another, irregardless of year. More remarkably there was no pattern as to the types of goods with reduced (increased) price dispersion among years. In 2007 solar walkway lights had a disparity ratio of 3.74:1 on Yahoo! Shopping's site, with a price range of \$35 to \$131. In 2011 solar walkway lights still had the highest disparity ratio of 4.06 , however this time on Google Product Search, with a price range of $\$ 69$ to $\$ 17$. Not surprisingly as technology matures the absolute cost of goods trends down. In 2007 a GE refrigerator had the lowest price ratio on both Yahoo! Shopping's and Google Product Search sites, with a ratio of 1.22:1 and 1.20:1, respectively. In 2011 the GE refrigerator had among the higher price dispersion, 1.67 and 1.74 respectively. Imperial Loafers, previously with considerable price dispersion 2.06 and 2.41 respectively, had no dispersion on Yahoo Shopping, 1.00. However, price dispersion persisted on Google Product Search with a ratio of 1.23.

Overall price dispersion has decreased from 2007 to 2011 with the price dispersion ratio decreasing in 64\% of the items on Yahoo! Shopping and 60\% of the items on Google Product Search. However, price dispersion actually increased in $28 \%$ of the items on Yahoo! Shopping and $32 \%$ of the items on Google Product Search. So 
although comparison shopping sites should virtually eliminate search costs, and these agents are arguably reaching their tipping point the magnitude of the price disparity ratios over the array of goods included in this audit remains remarkable. This condition raises the question of why so many online marketers can continue to charge prices far in excess of what their online competitors charge for identical goods. Several factors, noted in the introduction, might explain price differentials among identical goods: (a) shoppers, or a segment of shoppers, do not know about the price search and comparisons sites, or (b) if they are familiar with them, shoppers or a segment of shoppers do not frequently or routinely use them.

Table 1 Price Disparity among Online Sellers of Identical Consumer Durables - Yahoo! Shopping

\begin{tabular}{|c|c|c|c|c|c|c|c|}
\hline & \multicolumn{3}{|c|}{ Yahoo Shopping 2007} & \multicolumn{3}{|c|}{ Yahoo Shopping 2011} & \multirow{2}{*}{$\begin{array}{c}\text { Ratio } \\
\text { Diff. }\end{array}$} \\
\hline Product & High & Low & Ratio & High & Low & Ratio & \\
\hline Cordless Phone (Panasonic) & 179 & 119 & 1.5 & 117 & 60 & 1.95 & 0.45 \\
\hline Refrigerator (GE) & 2,800 & 2,295 & 1.22 & 2,400 & 1,440 & 1.67 & 0.45 \\
\hline Patio Chair (Faulkner) & 140 & 109 & 1.28 & 330 & 210 & 1.57 & 0.29 \\
\hline 65 Gal. Waste Container (Rubbermaid) & 167 & 135 & 1.24 & 304 & 204 & 1.49 & 0.25 \\
\hline Cordless Drill/Driver Kit (DeWalt) & 133 & 90 & 1.48 & 142 & 90 & 1.58 & 0.10 \\
\hline Watch (Seiko) & 250 & 120 & 2.08 & 382 & 180 & 2.12 & 0.04 \\
\hline Commercial Steam Vacuum (Hoover) & 364 & 277 & 1.31 & 264 & 198 & 1.33 & 0.02 \\
\hline 26" Expandable Luggage (Travelpro) & 170 & 123 & 1.38 & 153 & 111 & 1.38 & $0.00-$ \\
\hline Child Car Seat (Britax) & 300 & 234 & 1.28 & 230 & 180 & 1.28 & 0.00 \\
\hline Electric Shaver (Braun) & 180 & 125 & 1.44 & 280 & 205 & 1.37 & $(0.07)$ \\
\hline Sewing Machine (Singer) & 200 & 159 & 1.26 & 200 & 173 & 1.16 & $(0.10)$ \\
\hline Ball Upright Vacuum (Dyson) & 600 & 397 & 1.51 & 550 & 418 & 1.32 & $(0.19)$ \\
\hline DVD Player (Panasonic) & 125 & 85 & 1.47 & 60 & 48 & 1.25 & $(0.22)$ \\
\hline Food Processor (Cuisinart) & 229 & 154 & 1.49 & 180 & 147 & 1.22 & $(0.27)$ \\
\hline Laser Printer (HP LaserJet) & 129 & 90 & 1.43 & 160 & 140 & 1.14 & $(0.29)$ \\
\hline Soccer Cleat (Adidas) & 125 & 80 & 1.56 & 110 & 90 & 1.22 & $(0.34)$ \\
\hline Laptop (Sony VAIO) & 3,350 & 2,148 & 1.56 & 610 & 526 & 1.16 & $(0.40)$ \\
\hline Stereo Receiver (Sony) & 360 & 220 & 1.64 & 230 & 187 & 1.23 & $(0.41)$ \\
\hline Electric Toothbrush (OralB) & 140 & 85 & 1.65 & 100 & 90 & 1.11 & $(0.54)$ \\
\hline MP3 Player (Ipod Nano) & 245 & 125 & 1.96 & 150 & 135 & 1.11 & $(0.85)$ \\
\hline Imperial Loafers (Florsheim) & 169 & 82 & 2.06 & 170 & 170 & 1.00 & $(1.06)$ \\
\hline Digital Camera (Nikon) & 303 & 109 & 2.78 & 150 & 120 & 1.25 & $(1.53)$ \\
\hline Bike Trailer (Schwinn) & 260 & 100 & 2.60 & 230 & 218 & 1.06 & $(1.54)$ \\
\hline 50" Plasma TV (Panasonic) & 4,126 & 1,500 & 2.75 & 1,045 & 888 & 1.18 & $(1.57)$ \\
\hline Walk Light (Malibu) & 131 & 35 & 3.74 & 20 & 15 & 1.33 & $(2.41)$ \\
\hline
\end{tabular}

${ }^{1}$ Ratio of the highest price to lowest price if lowest $=1$. 
Table 2 Price Disparity among Online Sellers of Identical Consumer Durables Google Product Search

\begin{tabular}{|l|c|c|c|c|c|c|c|}
\hline \multicolumn{1}{|c|}{ Product } & \multicolumn{2}{|c|}{ Google Product Search 2007 } & \multicolumn{2}{c|}{ Google Product Search 2011 } & \multicolumn{2}{c|}{ Ratio } \\
\hline & High & Low & Ratio & High & Low & Ratio & Diff. \\
\hline Walk Light (Malibu) & 139 & 50 & 2.78 & 69 & 17 & 4.06 & 1.28 \\
\hline Cordless Phone (Panasonic) & 161 & 111 & 1.45 & 139 & 60 & 2.32 & 0.87 \\
\hline Electric Shaver (Braun) & 228 & 150 & 1.52 & 380 & 182 & 2.09 & 0.57 \\
\hline Commercial Steam Vacuum (Hoover) & 366 & 247 & 1.48 & 400 & 197 & 2.03 & 0.55 \\
\hline Refrigerator (GE) & 2,799 & 2,341 & 1.2 & 2,633 & 1,515 & 1.74 & 0.54 \\
\hline Sewing Machine (Singer) & 190 & 150 & 1.27 & 258 & 150 & 1.72 & 0.45 \\
\hline Stereo Receiver (Sony) & 300 & 209 & 1.44 & 320 & 170 & 1.88 & 0.44 \\
\hline Electric Toothbrush (OralB) & 140 & 60 & 2.33 & 240 & 90 & 2.67 & 0.34 \\
\hline Soccer Cleat (Adidas) & 101 & 76 & 1.33 & 110 & 80 & 1.38 & 0.05 \\
\hline Laptop (Sony VAIO) & 3,309 & 2,115 & 1.56 & 800 & 500 & 1.6 & 0.04 \\
\hline Child Car Seat (Britax) & 300 & 220 & 1.36 & 230 & 172 & 1.34 & $(0.02)$ \\
\hline Patio Chair (Faulkner) & 160 & 87 & 1.84 & 290 & 170 & 1.71 & $(0.13)$ \\
\hline 65 Gal. Waste Container (Rubbermaid) & 205 & 120 & 1.75 & 240 & 155 & 1.55 & $(0.20)$ \\
\hline MP3 Player (Ipod Nano) & 336 & 165 & 2.04 & 200 & 115 & 1.74 & $(0.30)$ \\
\hline Food Processor (Cuisinart) & 229 & 123 & 1.86 & 230 & 149 & 1.54 & $(0.32)$ \\
\hline DVD Player (Panasonic) & 126 & 60 & 2.1 & 79 & 48 & 1.65 & $(0.45)$ \\
\hline Watch (Seiko) & 400 & 149 & 2.68 & 261 & 120 & 2.18 & $(0.50)$ \\
\hline Bike Trailer (Schwinn) & 260 & 118 & 2.2 & 320 & 218 & 1.47 & $(0.73)$ \\
\hline Ball Upright Vacuum (Dyson) & 600 & 277 & 2.17 & 550 & 418 & 1.32 & $(0.85)$ \\
\hline Laser Printer (HP LaserJet) & 223 & 65 & 3.43 & 305 & 129 & 2.36 & $(1.07)$ \\
\hline Imperial Loafers (Florsheim) & 169 & 70 & 2.41 & 170 & 138 & 1.23 & $(1.18)$ \\
\hline 26" Expandable Luggage (Travelpro) & 340 & 123 & 2.76 & 170 & 113 & 1.5 & $(1.26)$ \\
\hline Digital Camera (Nikon) & 372 & 120 & 3.1 & 190 & 105 & 1.81 & $(1.29)$ \\
\hline 50" Plasma TV (Panasonic) & 4,126 & 1,415 & 2.92 & 1,227 & 786 & 1.56 & $(1.36)$ \\
\hline Cordless Drill/Driver Kit (DeWalt) & 270 & 90 & 3 & 163 & 105 & 1.55 & $(1.45)$ \\
\hline Rail of the highest pris to & & & & &
\end{tabular}

${ }^{1}$ Ratio of the highest price to lowest price if lowest $=1$.

\section{Online Shopper Survey Sample Demographics}

Table 3 displays the demographic distributions of response for the survey sample. The similarities of proportions of respondents of each sex reflect the sample quota specifications. The responding sample tended to be more educated, affluent, and engaged in more up-scale occupations than the population from which the convenience sample was obtained.

Table 3 Demographic Distributions of the Sample

\begin{tabular}{|c|c|c|c|c|c|}
\hline & Number & Percent & & Number & Percent \\
\hline \multicolumn{6}{|l|}{ Sex } \\
\hline Male & 565 & 49.8 & Occupation & & \\
\hline Female & 570 & 50.2 & Professional & 168 & 14.8 \\
\hline Age & & & Executive, Managerial & 167 & 14.7 \\
\hline Under 35 & 411 & 36.2 & Technical, Administrative & 155 & 13.7 \\
\hline $35-50$ & 363 & 32.0 & Sales, Marketing & 146 & 12.9 \\
\hline Over 50 & 361 & 31.8 & Skilled, Semi-skilled & 117 & 10.3 \\
\hline Marital Status & & & Not Employed & 382 & 33.7 \\
\hline Married & 613 & 54.0 & Home Ownership & & \\
\hline Not Married & 522 & 46.0 & Owner & 768 & 67.7 \\
\hline Education & & & Renter & 367 & 32.3 \\
\hline High School Only & 266 & 23.4 & Family Income & & \\
\hline Some College & 316 & 27.8 & Under $\$ 40,000$ & 142 & 16.6 \\
\hline College Graduate & 378 & 33.3 & $\$ 40,000$ to $\$ 59,000$ & 117 & 14.5 \\
\hline Post-Graduate & 175 & 15.4 & $\$ 60,000$ to $\$ 79,000$ & 121 & 15.0 \\
\hline Employment & & & $\$ 80,000$ to $\$ 99,000$ & 160 & 19.8 \\
\hline Company Employed & 483 & 42.6 & $\$ 100,000$ to $\$ 139,000$ & 99 & 12.2 \\
\hline Education or Government & 164 & 14.4 & $\$ 140,000 \&$ Over & 170 & 21.0 \\
\hline Self-Employed & 106 & 9.3 & & & \\
\hline Not Employed & 382 & 33.7 & Total & 809 & 100.0 \\
\hline
\end{tabular}




\section{Computer and Internet Use}

Survey respondents registered the type of internet connection they had and the number of hours per week they spent using the computer at home and at work, time on the internet, and time actually shopping online. These results are contained in Table 4 and Table 5.

Table 4 Respondents' Internet Connection Methods

\begin{tabular}{|l|c|c|}
\hline \multicolumn{1}{|c|}{ Method } & Num. & Pct. \\
\hline Digital Cable & 718 & 63 \\
\hline Telephone DSL & 233 & 21 \\
\hline Telephone MODEM & 131 & 12 \\
\hline Satellite/Other & 53 & 5 \\
\hline Total & 1,135 & 100 \\
\hline
\end{tabular}

Table 5 Hours Spent Using the Computer*

\begin{tabular}{|c|c|c|}
\hline Activity & Num. & Pct. \\
\hline \multicolumn{3}{|l|}{ At Home } \\
\hline Less than 5 Hours & 377 & 33 \\
\hline 6 to 10 Hours & 308 & 27 \\
\hline 11 to 20 Hours & 291 & 26 \\
\hline More than 20 Hours & 159 & 14 \\
\hline \multicolumn{3}{|l|}{ At Work } \\
\hline Less than 1 Hour & 383 & 34 \\
\hline 1 to 10 Hour & 264 & 23 \\
\hline 11 to 20 Hour & 161 & 14 \\
\hline More than 20 Hour & 327 & 29 \\
\hline \multicolumn{3}{|c|}{ On the Internet or Web } \\
\hline Less than 5 Hours & 337 & 30 \\
\hline 6 to 10 Hours & 311 & 27 \\
\hline 11 to 20 Hours & 301 & 27 \\
\hline More than 20 Hours & 186 & 16 \\
\hline \multicolumn{3}{|c|}{ Shopping Online } \\
\hline Less than 1 Hour & 152 & 13 \\
\hline One Hour & 484 & 43 \\
\hline Two Hours & 199 & 18 \\
\hline 3 or More Hours & 300 & 26 \\
\hline
\end{tabular}

$* \mathrm{~N}=1,135$

It should be recalled that the sample quota specifications required respondents to have made at least two online purchases in the past year. Thus, it might be expected that they would be relatively frequent users of computers and the internet. About 40 percent used the computer at home more than 10 hours per week. Nearly 3 out of 10 spend over half their work week on the computer. Time on the internet was also substantial, with more than 3 of 10 spending over 10 hours per week on the net.

Time spent shopping online was also substantial. Only 13 percent said they spend less than 1 hour a week shopping on the web, while over a fourth indicated they spend 3 or more hours a week so engaged. This group, then, might be regarded as experienced computer users and online shoppers.

\section{Online Purchase Values}

Respondents recorded the value of their most expensive purchase in the past year as well as the approximate total value of all online buying for that period. These data, displayed in Table 6, also represent high levels of purchase behavior. Only slightly more than 1 in 5 indicated their most expensive purchase was $\$ 75$ or less, with about the same proportion reporting total purchases for the year of $\$ 200$ or less. 
Table 6 Value of Online Purchases in the Past Year*

\begin{tabular}{|l|c|c|}
\hline \multicolumn{1}{|c|}{ Types of Purchase } & Num. & Pct. \\
\hline \multicolumn{1}{|c|}{ Most Expensive Purchase } & & 21 \\
\hline \$75 or Less & 241 & 23 \\
\hline \$7 to $\$ 150$ & 260 & 16 \\
\hline \$151 to $\$ 250$ & 183 & 20 \\
\hline \$251 to $\$ 500$ & 228 & 20 \\
\hline More than $\$ 500$ & 223 & 22 \\
\hline$\quad$ Total of All Purchases & & 28 \\
\hline \$200 or Less & 247 & 28 \\
\hline \$201 to $\$ 400$ & 209 & 20 \\
\hline \$101 to $\$ 1,0001$ to $\$ 2,000$ & 315 & \\
\hline More than $\$ 2,000$ & 142 & \\
\hline
\end{tabular}

$* \mathrm{~N}=1,135$

On the high side of the spectrum, a fifth of all respondents reported their most costly purchase at more than $\$ 500$ and the same fraction said they had spent more than $\$ 2,000$ in total during the previous year. Once again, these data encourage the conclusion that those responding to the survey were frequent and purposeful online buyers of consumer goods, rather than merely casual shoppers of Web offerings.

\section{Online Shopping Behaviors}

A list of 16 online shopping actions or practices is shown in Table 6. Respondents indicated how often they performed each using a verbal frequency scale ranging from 1, Very Often, to 5, Never. Both the median and modal values are shown in Table 7.

Using a search site to locate products was the single most common action online shoppers reported, with recording tracking numbers for delivery of purchases close behind. Respondents also reported they often check more than one site for comparisons, bought mainly from favorite online sellers, and read online reviews before buying. Among the actions least often taken, respondents reported rarely if ever visited coupon sites, "personalized" seller sites with their own preferences, wrote online reviews or sent email of product descriptions from seller sites to others.

In view of the fact that using a search engine or site to locate the goods they wanted was the most common practice listed in this study and checking more than one site to make comparisons was the third most often action taken of the 16 listed, it might be assumed that price considerations would be a major factor underlying these searches and comparisons. Quite surprisingly, this turned out not necessarily to be the case.

Table 7 Median and Modal Frequency Ratings of Online Shopping Actions*

\begin{tabular}{|l|l|c|}
\hline \multicolumn{1}{|c|}{ Statement } & Median & Mode \\
\hline Use a search engine or search site to locate what you want. & 1 & 1 \\
\hline Record a tracking number when available and track delivery. & 2 & 1 \\
\hline Check more than one site to make comparisons. & 2 & 2 \\
\hline Buy mainly from a "favorite" online seller. & 2 & 2 \\
\hline Read online reviews of the goods before buying. & 3 & 2 \\
\hline Go to one or more price comparison sites or sellers. & 3 & 3 \\
\hline Add items to the "shopping cart," then leave the site, returning later. & 3 & 3 \\
\hline Add items to the "shopping cart," then leave without ever returning. & 3 & 3 \\
\hline Select a delivery method that's faster than the least costly one. & 3 & 4 \\
\hline Return to a site several times to see if better prices are offered. & 3 & 4 \\
\hline Allow the online merchant to send you email ads and sale bulletins. & 4 & 4 \\
\hline Link to a site from an email advertisement you received. & 4 & 4 \\
\hline Send email product descriptions from the site to family or friends. & 4 & 5 \\
\hline Write reviews of previous purchases when the site allows it. & 4 & 5 \\
\hline Register with the seller's site or "personalize" the seller's web page. & 4 & 5 \\
\hline Visit an online coupon service site to find discount coupons or "codes." & 4 & 5 \\
\hline
\end{tabular}

*N = 1,135 - 5-Point Scale: 1=Very Often, 2=Often, 3=Sometimes, 4=Rarely, 5=Never

408 Copyright by author(s) Creative Commons License CC-BY

2013 The Clute Institute 


\section{Online Price Comparisons}

Ten of the most popular online price comparison websites were listed in alphabetical order and respondents were asked how many times in the past year they had visited each site. The results are contained in Table 8. Yahoo! Shopping proved to be the most popular product search and price comparison site listed, with the responding sample divided almost equally between those who never visited, those who visited between 1 and 10 times, and those who visited more than 10 times.

Some 22 percent said they had visited BizRate at least once while 19 percent indicated so for the Google Product Search site. Less than 5 percent had visited either of these two sites more than 10 times. More than 9 out of 10 shoppers had never at all visited the remaining 8 product search and price comparison sites. Therefore those that do use such facilities depend mainly on one site, as nearly all the reported use is confined to just 3 of the 10 sites listed in this survey. In summary, these results indicate frequent use of a search engine or site to locate goods and frequent checking of more than one site to make comparisons, as reported in Table 6 , have more to do with finding the right product or product features than obtaining the best price.

Table 8 Percentage Visiting Price Comparison Sites in the Past Year*

\begin{tabular}{|l|c|c|c|}
\hline \multicolumn{1}{|c|}{ Site } & Never & $\mathbf{1}$ to 10 & Over 10 \\
\hline Yahoo! Shopping & 36 & 34 & 29 \\
\hline BizRate & 78 & 19 & 4 \\
\hline Google & 81 & 15 & 2 \\
\hline PriceGrabber & 90 & 9 & 1 \\
\hline NexTag & 91 & 7 & 1 \\
\hline DealTime & 94 & 5 & 0 \\
\hline PriceScan & 94 & 5 & 0 \\
\hline PriceRunner & 96 & 4 & 0 \\
\hline MetaPrice & 97 & 2 & 0 \\
\hline PepperJam & 98 & 1 & \\
\hline
\end{tabular}

$* \mathrm{~N}=1,135$

\section{CONCLUSIONS}

This study was designed to gain insight into online buyers' true usage and dependence on product search and price comparison websites. Other research and statistical evidence indicates that ShopBot usage is reaching its tipping point; therefore price disparity should be nearly absolved. However, an audit of consumer durable goods indicates that significant price dispersion persists. Furthermore, although price dispersion is trending down it is doing so slowly. In fact, approximately $30 \%$ of items audited saw increased price dispersion. Our results that the bottom 1/3 of our sample had never visited the most popular Yahoo! Shopping, while the top third had visited 10 plus times, suggests that despite the explosion of ShopBot usage nationwide, this explosion appears to currently be limited to a segment of the population that is innovative and/or price sensitive and/or more trusting of on-line retailers.

However, given that the tipping point of shopping comparison sights appears inevitable the segment of the population still ignorant of price differences will not remain so. Furthermore, the size of the segment of the population aware of ShopBots but not frequent users should also decrease. Therefore, as evidenced by the reduction in price dispersion from 2007 to 2011 greater direct price competition among sellers and a substantial growth in price rationalization should continue. Online marketers would then require strategies to protect against vigorous price competition and shrinking margins. Those strategies consist mainly of methods to distinguish the vendor from others and to create and intensify trust and loyalty.

\section{Shopper Price Comparisons}

The use of consumer product search and price comparison websites was remarkably lower than expected considering the most current exploding usage statistics for the top price comparison sites. These results do not necessarily mean that the segment of online shoppers that does not use ShopBots is price insensitive. As our results 
indicate consumers often check more than one site to make comparisons. However given the benefits of price comparison sites, in terms of simplicity, speed, and convenience why are consumers going from one site to another and not using a price comparison site?

This creates something of a conundrum: On the one hand, respondents claim they often use search engines to locate goods and visit more than one site to make comparisons. On the other, they seldom use price comparison websites to compare prices. While there may be more reasons for this apparent contradiction, two possible explanations come to mind. The most obvious explanatory factor would be if there were actually very small price disparities among like goods. If price differentials were negligible, shoppers might not find it worth their while to systematically compare prices. Given the remarkably large price disparities identified in this study, that explanation must be rejected.

A close corollary to the "no-large-price-differences" explanation is the perception by online shoppers that prices are probably very similar. It is a basic tenet of consumer psychology that people make product choices according to their perceptions of the goods, rather than the actual physical or chemical constituents. If that be the case here, then low use levels for price comparison sites result, in substantial measure, from either (a) ignorance of the amount of price disparity from one seller of identical goods to another, or (b) unfamiliarity with the ease and simplicity of using price comparison sites. But what happens when they find out?

\section{Price Rationalization}

And they will find out. The process by which online shoppers will gain familiarity and experience with price comparison sites and facilities is predictable because it is inherent in the ever-increasing use of search engines in general. Even though a shopper may not be deliberately seeking price comparison, conducting a product search using a site such as Google automatically yields links that typically include not only Google Product Search, but also a host of other such sites, such as shop.com, BizRate, or MSN Shopping. It is virtually impossible for online shoppers to do any sort of product search without becoming aware of price comparison facilities, if not deliberately, then purely by accident.

The most popular product search and price comparison sites initially list the results of a search by "relevance" or "best match." In other words, they list first those products whose identifiers most closely "fit" the specification the shopper entered, be that generic product name, brand name, or specific model number. Virtually all these sites use a "Sort by ..." pull down menu allowing the shopper to sort from lowest to highest or highest to lowest price, as well as by other criteria. Once a shopper has done such a sort, for any product of substantial value, it becomes very obvious there are large price differentials. The consumer need not be especially astute to realize that if there are such price differences for this product, there are probably large disparities among sellers of other products, as well. Thus, any naiveté will give way quickly to greater understanding.

There is some degree of circularity involved in the process of becoming familiar and experienced with price comparison facilities. Use of product search sites may lead to recognition of price differentials and the need to compare prices. The need to compare prices may then lead to more frequent use, and perhaps a wider array of product search and price comparison sites. And so the circle goes.

\section{M-Commerce, Tablets, and Apps}

With lighter, smaller, and location independent (WiFi and 3G or 4G wireless) devices with long battery lives such as smart phones and tablets, online shopping is now unchained from the desk at work or at home. Shoppers can now cuddle with their online device in bed, in front of the televison, or take it with them on their shopping trip to the bricks and mortar retailers. This kind of fluid online and portable hybrid shopping, the value of price comparisons on the fly becomes clear. New apps such as Catalog Spree for the iPad, shoppers can have access to hundreds of catalogs from one application. A quick test of the Yahoo! Shopping and Google Product Search portals using smart-phones and tablets (both on the Apple and Android platforms) suggests that the ease of use and the added mobility will be game changers. In addition to these traditioal web-based price comparison sites, a number of product comparison apps available through the "App Store" amd "Android Market" enable users to scan bar 
codes at a store and compare prices for that product and similar products online and at other retailers. The pressure now seems to be on the traditional brick and mortar retailers as well as the online shopping sites to constantly scan the pricing landscape and position their products accordingly.

\section{Implications}

Still disparities among prices for identical goods are understandable when the sellers have conventional retail outlets in different locations. Even when such outlets are in close proximity to one another, differences in store atmospherics, customer service and assistance, store prestige and the overall shopping experience may compensate, in many shoppers' minds, for a higher price than might be available nearby. They may simply decide it is "worth it" to patronize the higher priced store.

Of the many factors that typically distinguish one traditional retail store from another, far fewer apply to online marketers. The vast majority of online marketers appear to provide almost identical product descriptions and displays, transaction and payment facilities, shipping options and return privileges. Thus, most online sellers of consumer goods should be vulnerable to direct price competition. However, price dispersion although declining, persists. Once consumers recognize the degree of price disparity, many higher-priced sellers could be forced out of the game by lower-priced competitors unless they distinguish themselves by customer relationship management or some other means.

\section{Customer Relationship Management (CRM)}

Customer relationship management incorporates all aspects of interaction marketers have with their customer, including both sales and service activities. Access to the internet and web are rapidly changing the way consumers shop and purchase. New technology such as Wireless Application Protocol will permit more and more consumers to interact with marketers and obtain product information instantly on their cell phones, smartphones, pagers and communicators. Viewed from the sellers' side of the equation, current and future communications methods offer online marketers exceptional opportunities not readily available to those who sell exclusively through so-called "brick and mortar" stores. Online marketers can personalize customers' shopping and buying experiences through relationship marketing.

Relationship marketing is a strategy focusing on the maintenance and improvement of relationships with current customers rather than the more traditional emphasis on acquiring new customers. It uses a wide array of marketing, communication, sales, and customer service techniques to identify named individual customers and create a relationship between the marketer and those customers.

\section{Patronage Loyalty}

It was noted earlier that on-line retailers differ in terms of perceived reputation and reliability and that these factors influence consumer trust. Trust is an essential element of successful e-commerce and can be enhanced and leveraged thru continued commitment (Walton et al. 2008). This indicates that patronage loyalty can perhaps compensate, in minds of customers, for a higher price than might be available from another e-retailer. Trust and loyalty may be enhanced by effective customer relationship management.

In this study, buyers rated the frequency with which they "Bought mainly from a favorite online seller." and "Checked more than one site to make comparisons." about equally. The typical respondent said they "Often" did both. This reveals a substantial degree of patronage loyalty. Perhaps the surest and most productive way for any online marketer to maintain higher margins would be to cement such patronage loyalty with thorough, effective database marketing.

Database Marketing

Database marketing, an offshoot of direct marketing, is a method of interactive marketing that uses databases of existing or potential customers to create personalized messages that promote a product or service. Any 
addressable medium can be used. A database typically includes names, email and/or postal addresses, purchase histories, previous transactional details, and perhaps additional geographic, demographic or psychographic data. These customer profiles are used to identify potential buyers and their preferences in order to target marketing communications more effectively.

Messages about products and services for which consumers have no interest or need are usually called "junk mail" or "spam" by the recipients. Such shotgun approaches to promotion typically earn the sender only the hostility and resentment of the consumers. By contrast, messages selectively targeted to those who are likely to have a need for the goods, and especially to previous customers or shoppers who expressed willingness to get such messages are likely to enjoy a far more hospitable reception. Such communications are helpful to intensify patronage loyalty.

\section{Special Loyalty Programs}

While they share many of the same objectives and methods, some loyalty programs have special features and specific names that identify their characteristics. These special marketing programs can be seen as subsets of both customer relationship management and database marketing. (Gordon, 2002; Massad, Heckman, \& Crowston, 2006; Pan, 2003; Plakoyiannaki \& Tzokas, 2002) Used effectively, they also support patronage loyalty to online marketers.

\section{Frequency Marketing}

Any program to entice customers to purchase frequently or to reward them for doing so. Frequency programs, also called loyalty programs, typically provide customers with rewards based on how frequently they buy. The benefits to patrons have to be sufficient to make customers want to join, to provide the required information about them, and to maintain membership. The information sought may simply be the consumer's name and email address, or it may be a much more substantial set of demographic and lifestyle data. Once a customer has "joined" and earned "points" or received other potential benefits for continued patronage, loyalty may be significantly enhanced.

\section{Affinity Marketing}

A program to target a specific category of customer based on occupation, social membership, religious preference, or establishing buying patterns. Messages may be delivered via e-mail communications or offline media. This form of relationship marketing assists online marketers to target more effectively. An additional advantage is gained by the personalization of marketing communications because of the recipients' identification with the specific affinity group to which they belong. To the degree members value the group affiliation, they may increase their loyalty to the marketer recognizing their group identity.

\section{Customer Retention}

Patronage loyalty of the kind that will offer online marketers some protection against strident price competition is all about customer retention. (Berger \& Nasr, 1998) This is the essence of customer relationship management. In practice, increased patronage loyalty and extended customer retention are almost synonymous. Given the persistent mistrust in unknown online retailers, the development of customer loyalty today may insulate retailers from more direct price competition.

\section{Customer Lifetime Value}

The first step is to categorize customers according to worth to the marketer. (Gordon, 1999) The marketer can then choose which relationships deserve greater attention and investment, as well as which require a different approach. 


\section{Customer Retention Measurement}

A company's customer retention rate is simply the percentage of customers at the beginning of a fiscal year that remain customers at the end of it. (Dawkins \& Reichheld, 1990) For instance, an increase from $80 \%$ to $90 \%$ in retention rate means doubling the average life of a customer relationship from 5 to 10 years. Comparisons between products, market segments, or over time can be measured by this ratio.

\section{$\underline{\text { Reasons for Defection }}$}

There are several methods for learning the reasons customers defect. (Choi, Kim, Kim, \& Kim, 2006; Hicks, Page, Behe, Dennis, \& Fernandez, 2005) Surveys, focus groups and individual interviews of former, as well as current customers are helpful. These methods are available to both online and offline marketers, but online marketers have a unique source of information: buyer ratings and evaluations.

In this study, the typical respondents said they sometimes or often read reviews, although they rarely or never wrote them. As with other forms of complement and complaint recording, it seems likely that those who are extremely favorable and especially those who are extremely unfavorable to the goods or seller will provide evaluations at higher rates than those at medium levels of satisfaction or dissatisfaction.

Just as online shoppers have access to online buyer ratings and evaluations, so, too, do online marketers. This is a rich source of information about seller performance, both that of the online marketer and that of competitors. Analysis of both favorable and unfavorable customer ratings and evaluations can shed light on why customers remain loyal or defect. While summary analysis of ratings may be revealing, content analysis of text evaluations and comments may be richer and more meaningful. It is important to look not only at what is viewed unfavorably by customers so negative factors can be corrected, but also to study what was seen as positive, so those features can be extended and projected to other products, customers, and situations.

\section{Corrective Action Plans}

There is a big difference between knowing what is wrong and doing something about it! The more strident the complaints, the more necessary it is to take corrective action. While individual complaints may be harbingers of problems yet to arise, they seldom deserve much attention. It is to the patterns of response that marketers must react promptly and effectively. Sometimes the remedy is as simple as changing the menu on the incoming automated call director. But at other times the remedial action may be as far-reaching as abandoning an entire delivery system in favor of a more effective one. Unfortunately, there is often a high correlation between how major the remedy is and how important it is to make the change in order to maintain customer loyalty.

\section{SUMMARY}

- $\quad$ A segment of current online shoppers do not often use price comparison sites.

- Very substantial price discrepancies among online sellers of consumer durable goods do currently exist.

- $\quad$ Price discrepancy is declining, although not rapidly.

- $\quad$ Consumer awareness of existing price disparities will unquestionably increase with the increase in use of search sites and facilities.

- $\quad$ Price discrepancies will become increasingly apparent with the increase in use of product search sites.

- Increased price competition is virtually inevitable, concomitant with growth in familiarity and experience with price comparison sites.

- $\quad$ Despite similarities among online vendors, online shoppers do report increased trust and loyalty to their "favorite" sellers.

- The most potent protection against direct price competition appears to be creation of patronage loyalty through customer relationship management.

- $\quad$ Database marketing offers the most promising avenue for both obtaining new customers and building existing customer loyalty. 
- $\quad$ Marketing programs such as frequency marketing and affinity marketing can be used effectively to enhance patronage loyalty.

- Customer retention is best insured by (a) assessing customer lifetime value, (b) measuring customer retention, (c) discovering reasons for defection, and (d) taking corrective action.

\section{AUTHOR INFORMATION}

Kirsten A. Passyn is an Associate Professor of Marketing at the Franklin P. Perdue School of Business, Salisbury University. Dr. Passyn's Ph.D. is from Pennsylvania State University. E-mail: kapassyn@ @alisbury.edu

Memo Diriker is the Director of the Business, Economic, and Community Outreach Network (BEACON) at the Perdue School of Business, Salisbury University. His D.B.A. is from the University of Memphis. E-mail: mfdiriker@salisbury.edu

Robert B. Settle is a Professor of Marketing at the Franklin P. Perdue School of Business, Salisbury University, Salisbury Maryland. Dr. Settle earned his Ph.D. from the University of California, Los Angeles. E-mail: rbsettle@salisbury.edu (Corresponding author)

\section{REFERENCES}

1. Berger, P. D., \& Nasr, N. I. (1998). Customer lifetime value: Marketing models and applications. Journal of Interactive Marketing, 12(1), 17.

2. Brynjolfsson, E., Dick, A., \& Smith, M. D. (2004). Search and Product Differentiation at an Internet Shopbot.

3. $\quad$ Burdett, K., \& Judd, K. L. (1983). Equilibrium Price Dispersion. Econometrica (pre-1986), 51(4), 955.

4. Chevalier, J., \& Goolsbee, A. (2003). Measuring Prices and Price Competition Online: Amazon.com and BarnesandNoble.com. Quantitative Marketing and Economics, 1(2), 203.

5. Choi, D. H., Kim, C. M., Kim, S.-I., \& Kim, S. H. (2006). Customer Loyalty and Disloyalty in Internet Retail Stores: Its Antecedents and its Effect on Customer Price Sensitivity. International Journal of Management, 23(4), 925.

6. Clay, K., Krishnan, R., \& Wolff, E. (2001). Prices and price dispersion on the Web: Evidence from the the online book industry. The Journal of Industrial Economics, 49(4), 521.

7. Dawkins, P. M., \& Reichheld, F. F. (1990). Customer Retention as a Competitive Weapon. Directors and Boards, 14(4), 42.

8. Degeratu, A. M., Rangaswamy, A., \& Wu, J. (2000). Consumer choice behavior in online and traditional supermarkets: The effects of brand name, price, and other search attributes. International Journal of Research in Marketing, 17(1), 55.

9. Gordon, I. (1999). Relationship Marketing: New Strategies, Techniques and Technologies to Win Customers You Want and Keep Them Forever. New York: John Wiley and Sons.

10. Gordon, I. (2002). Best Practices: Customer Relationship Management. Ivey Business Journal Online, 1.

11. Haubl, G., \& Trifts, V. (2000). Consumer decision making in online shopping environments: The effects of interactive decision aids. Marketing Science, 19(1), 4.

12. Hicks, J. M., Page, T. J., Jr., Behe, B. K., Dennis, J. H., \& Fernandez, R. T. (2005). Delighted Consumers Buy Again. Journal of Consumer Satisfaction, Dissatisfaction and Complaining Behavior, 18, 94.

13. Kocas, C. (2002). Evolution of prices in electronic markets under diffusion of price-comparison shopping. Journal of Management Information Systems, 19(3), 99.

14. Kocas, C. (2005). A Model of Internet Pricing Under Price-Comparison Shopping. International Journal of Electronic Commerce, 10(1), 111.

15. Lumry, S. (2011). Whats the Estimated Annual Value of Online Shopping in North America? Retrieved 12/20/2011 from http://www.quora.com/Whats-the-estimated-annual-value-of-online-shopping-in-NorthAmerica

16. Massad, N., Heckman, R., \& Crowston, K. (2006). Customer Satisfaction with Electronic Service Encounters. International Journal of Electronic Commerce, 10(4), 73. 
17. Pan, C. W. T. a. S. L. (2003). Managing e-transformation in the public sector: an e-government study of the Inland Revenue Authority of Singapore (IRAS). European Journal of Information Systems, 12(4), 269.

18. Plakoyiannaki, E., \& Tzokas, N. (2002). Customer relationship management: A capabilities portfolio perspective. Journal of Database Marketing, 9(3), 228.

19. Ratchford, B. T., Pan, X., \& Shankar, V. (2003). On the efficiency of Internet markets for consumer goods. Journal of Public Policy \& Marketing, 22(1), 4.

20. Schiffman, L. G., \& Kanuk, L. L. (2007). Consumer Behavior (9th ed.). Upper Saddle River, NJ: Pearson Prentice Hall.

21. Sen, R., King, R. C., \& Shaw, M. J. (2006). Buyers' Choice of Online Search Strategy and Its Managerial Implications. Journal of Management Information Systems, 23(1), 211-238.

22. Shankar, V., Rangaswamy, A., \& Putaseri, M. (1999). Customer Price Sensitivity and the Online Medium. Unpublished Working Paper. Pennsylvania State University, e-Business Research Center.

23. Stahl, D. O., II. (1989). Oligopolistic Pricing With Sequential Consumer Search. The American Economic Review, 79(4), 700.

24. Varian, H. R. (1980). A Model of Sales. The American Economic Review, 70(4), 651.

25. Vijayasarathy, L., \& Joseph, J. Do Internet Shopping Aids Make a Difference? An Empirical Investigation [Electronic Version]. Electronic Markets, 11, 75-83. Retrieved 07/25/07 from www.electronicmarkets.org 
NOTES 